\title{
Shared Medical Appointments and Prediabetes: The Power of the Group
}

\author{
Apbrodite Papadakis, $M D^{1,2}$ \\ Elizabeth R. Pfob, $P b D^{2}$ \\ Bo $H u, P b D^{3}$ \\ Xiaobo Liu, $\mathrm{PbD}^{3}$ \\ Michael B. Rotbberg, MD, MPH \\ Anita D. Misra-Hebert, MD, \\ $\mathrm{MPH}^{2,3}$ \\ 'Department of Family Medicine \\ Cleveland Clinic, Cleveland, Ohio \\ ${ }^{2}$ Center for Value-Based Care Research \\ Cleveland Clinic, Cleveland, Ohio \\ ${ }^{3}$ Department of Quantitative Health \\ Sciences, Cleveland Clinic, Cleveland, \\ Ohio
}

Conflicts of interest: Dr Misra-Hebert reports funding from the Agency for Healthcare Research and Quality Ko8 HSO24128 and reports grants from NHLBI, Novo Nordisk Inc, Merck Inc, and Boebringer Ingelbeim Pharmaceuticals Inc outside the submitted work. No other conflicts of interest reported by the other authors.

\section{CORRESPONDING AUTHOR}

Aphrodite Papadakis Beachwood Family Health Center 26900 Cedar Rd, Suite 22N

Beachwood, OH 44122

papadaa@ccf.org

\begin{abstract}
Shared medical appointments, which allow greater access to care and provide peer support, may be an effective treatment modality for prediabetes. We used a retrospective propensity-matched cohort analysis to compare patients attending a prediabetes shared medical appointment to usual care. Primary outcome was patient's weight change over 24 months. Secondary outcomes included change in hemoglobin $A_{1 c}$ low density lipoprotein, and systolic blood pressure. The shared medical appointments group lost more weight (2.88 kg vs 1.29 $\mathrm{kg}, P=.003)$, and achieved greater reduction in hemoglobin $A_{1 c}(-0.87 \%$ vs $+0.87 \%, P=.001)$ and systolic blood pressure $(-4.35 \mathrm{mmHg}$ vs $+0.52 \mathrm{mmHg}$, $P=.044)$. The shared medical appointment model can be effective in treating prediabetes.
\end{abstract}

Ann Fam Med 2021;19:258-261. https://doi.org/10.1370/afm.2647.

\section{INTRODUCTION}

$\mathrm{M}$ ore than 1 in 3 adults have prediabetes, and nearly three-quarters of these will progress to diabetes. ${ }^{1,2}$ Diabetic complications such as microvascular dysfunction may already be present in patients with prediabetes. ${ }^{3}$ Treatment of prediabetes, primarily weight loss, is effective, yet only $23 \%$ of patients with prediabetes are treated. ${ }^{4}$

Patients may be undertreated due to lack of physician awareness, lack of resources, and lack of time. Shared medical appointments have the potential to reach more patients and provide additional resources, including peer support. Shared medical appointments are group visits that combine a medical visit with education and discussion around a common condition. ${ }^{5}$ In type 2 diabetes, shared medical appointments have been shown to improve glycemic control and/or slow disease progression, in some cases more than usual care. ${ }^{3,5-7}$ Only 1 study, by Cole et al, has evaluated a shared medical appointment for prediabetes; both groups lost weight at 3 months, and regained some at 1 year. The weight loss difference between the 2 groups was not statistically significant. ${ }^{8}$

This study aims to evaluate the effectiveness of shared medical appointments for prediabetes compared with a matched cohort of patients receiving usual care. We hypothesized that patients in the shared medical appointment group would lose more weight than controls. The success of shared medical appointments in diabetic patients, perhaps because of group support, led us to this hypothesis. Secondarily, we assessed the impact of attending a shared medical appointment vs usual care on glycosylated hemoglobin $\mathrm{A}_{\mathrm{cc}}\left(\mathrm{HbA}_{\mathrm{lc}}\right)$, low density lipoprotein (LDL) cholesterol, and systolic blood pressure (SBP).

\section{METHODS}

This was a retrospective cohort study using electronic medical record data of patients who had at least 2 office visits during the study period with an internist, family physician, or nurse practitioner at 1 suburban primary 
care practice in the Cleveland Clinic Health System from June 2012 through December 2016.

The shared medical appointment patients had an initial shared medical appointment (index visit) during the study period. This appointment lasted 90 minutes, included 8-10 patients, and was facilitated by a family physician and diabetes educator. During this initial appointment each patient received 10-15 minutes of individual discussion with the cofacilitators. Pertinent laboratory test results were reviewed with the group and personal goals were set.

Our control population consisted of patients with prediabetes who were seen for either a wellness exam (International Classification of Diseases [ICD 9/10] V70.0/ Z00.00), prediabetes (790.21-.22/R73.02, 790.29/ R73.03), or weight management (783.21/Z71.3, 278.00/ E66.9-E66.01) within 1 month of the index visit. All patients had a $\mathrm{HbA}_{\mathrm{cc}}$ of $5.7 \%$ to $6.4 \%$ result from up to 90 days before the index visit and were excluded if they were aged $<18$ years, pregnant, had a prescription for any weight loss medication, or had a diagnosis of diabetes before their first $\mathrm{HbA}_{1 \mathrm{c}}$ test during the study period.

We used descriptive statistics (Pearson's $\chi^{2}$ test and 2 sample $t$-tests) to compare the unmatched shared medical appointment and control groups and 2:1 propensity matching to create comparable groups. We included baseline age, race, sex, body mass index (BMI), smoking status, statin use, metformin use,
$\mathrm{HbA}_{1 \mathrm{c}}$, and zip code (to estimate median income) in the propensity score. After propensity matching, general linear mixed effects regression models were performed to identify the effect of the shared medical appointment group on changes in weight, $\mathrm{HbA}_{1 \mathrm{c}}$, LDL, and SBP. All tests were performed at a significance level of 0.05. SAS 9.4 software (SAS Institute Inc) was used for analyses. This study was approved by the Institutional Review Board at Cleveland Clinic.

\section{RESULTS}

A total of 2,440 controls and 69 shared medical appointment patients were eligible for matching. Before matching, the shared medical appointment group had fewer White participants than the control group (52\% vs $65 \%, P=.006)$. There were no differences in age, baseline weight, $\mathrm{BMI}, \mathrm{HbA}_{1 \mathrm{c}}, \mathrm{LDL}, \mathrm{SBP}$, or smoking status. More patients in the shared medical appointment group were prescribed a statin $(8.7 \%$ vs $2.9 \%$, $P=.006)$ and metformin $(2.9 \%$ vs $0.25 \%, P<.001)$ before their first visit (Table 1).

The matched cohort included 135 control patients and 68 shared medical appointment patients (Table 1). Figure $1 \mathrm{~A}-\mathrm{D}$ shows the baseline through 24 -month outcomes based upon the linear mixed effect model. Over 24 months, shared medical appointment patients lost more weight than controls $(2.88 \mathrm{~kg}$ vs $1.29 \mathrm{~kg}$,

Table 1. Baseline Demographics

\begin{tabular}{|c|c|c|c|c|c|c|c|}
\hline \multirow[b]{2}{*}{ Characteristics } & \multicolumn{4}{|c|}{ Groups Before Matching } & \multicolumn{3}{|c|}{ Matched Groups } \\
\hline & $\begin{array}{c}\text { All } \\
(n=2,509)\end{array}$ & $\begin{array}{c}\text { SMA } \\
(n=69)\end{array}$ & $\begin{array}{c}\text { Control } \\
(n=2,440)\end{array}$ & $\begin{array}{c}P \\
\text { Value }\end{array}$ & $\begin{array}{l}\text { Matched Control } \\
\qquad(n=135)\end{array}$ & $\begin{array}{l}\text { Matched SMA } \\
\qquad(n=68)^{a}\end{array}$ & $\begin{array}{c}P \\
\text { Value }\end{array}$ \\
\hline Age, mean (SD), y & $60(13.2)$ & $60(9.6)$ & $60(13.3)$ & .736 & $60(15.2)$ & $60(9.6)$ & .860 \\
\hline \multicolumn{8}{|l|}{ Race, No. (\%) } \\
\hline White & $1,620(64.6)$ & $36(52.2)$ & $1,584(64.9)$ & .006 & $76(56.3)$ & $36(52.9)$ & .900 \\
\hline Black & $753(30)$ & $32(46.4)$ & $721(29.5)$ & & $57(42.2)$ & $31(45.6)$ & \\
\hline Asian/other & $136(5.4)$ & $1(1.4)$ & $135(5.5)$ & & $2(1.5)$ & $1(1.5)$ & \\
\hline \multicolumn{8}{|l|}{ Sex } \\
\hline Female, No. (\%) & $1,515(60.4)$ & $48(69.6)$ & $1467(60.1)$ & .110 & $100(74.1)$ & $47(69.1)$ & .460 \\
\hline Smokers ${ }^{b}$, No. (\%) & $185(7.5)$ & $3(4.3)$ & $182(7.6)$ & .320 & $4(3.0)$ & $3(4.4)$ & .690 \\
\hline Baseline weight, mean (SD), kg & $89(22.3)$ & $91(18.1)$ & $89(22.4)$ & .473 & $90(21.2)$ & $91(18.2)$ & .842 \\
\hline BMI, mean (SD), \% & $32(6.8)$ & $32(6.4)$ & $32(6.8)$ & .339 & $33(6.8)$ & $32(6.4)$ & .615 \\
\hline LDL, mean (SD), mg/dL & $108(36.6)$ & $110(30.9)$ & $108(37.3)$ & .669 & $113(32.5)$ & $109(30.3)$ & .560 \\
\hline $\mathrm{HbA}_{1 \mathrm{c}}$, mean (SD), \% & $6(0.2)$ & $6(0.2)$ & $6(0.2)$ & .203 & $6(0.2)$ & $6(0.2)$ & .729 \\
\hline SBP, mean (SD), mmhg & $129(16.1)$ & $132(15.0)$ & $129(16.1)$ & .103 & $129(17.3)$ & $132(14.9)$ & .215 \\
\hline Metformin use, No. (\%) & $8(0.3)$ & $2(2.9)$ & $6(0.3)$ & $<.001$ & $2(1.5)$ & $1(1.5)$ & .990 \\
\hline Statin use, No. (\%) & $77(3.1)$ & $6(8.7)$ & $71(2.9)$ & .006 & $9(6.7)$ & $5(7.4)$ & .860 \\
\hline $\begin{array}{l}\text { Median income, mean (SD), } \\
\text { USD, } \times 1000\end{array}$ & $62(20)$ & $61(21)$ & $62(19)$ & .500 & $60(22)$ & $62(22)$ & .572 \\
\hline
\end{tabular}


Figure 1 A-D. Outcomes of matched cohorts based on linear mixed effects model.
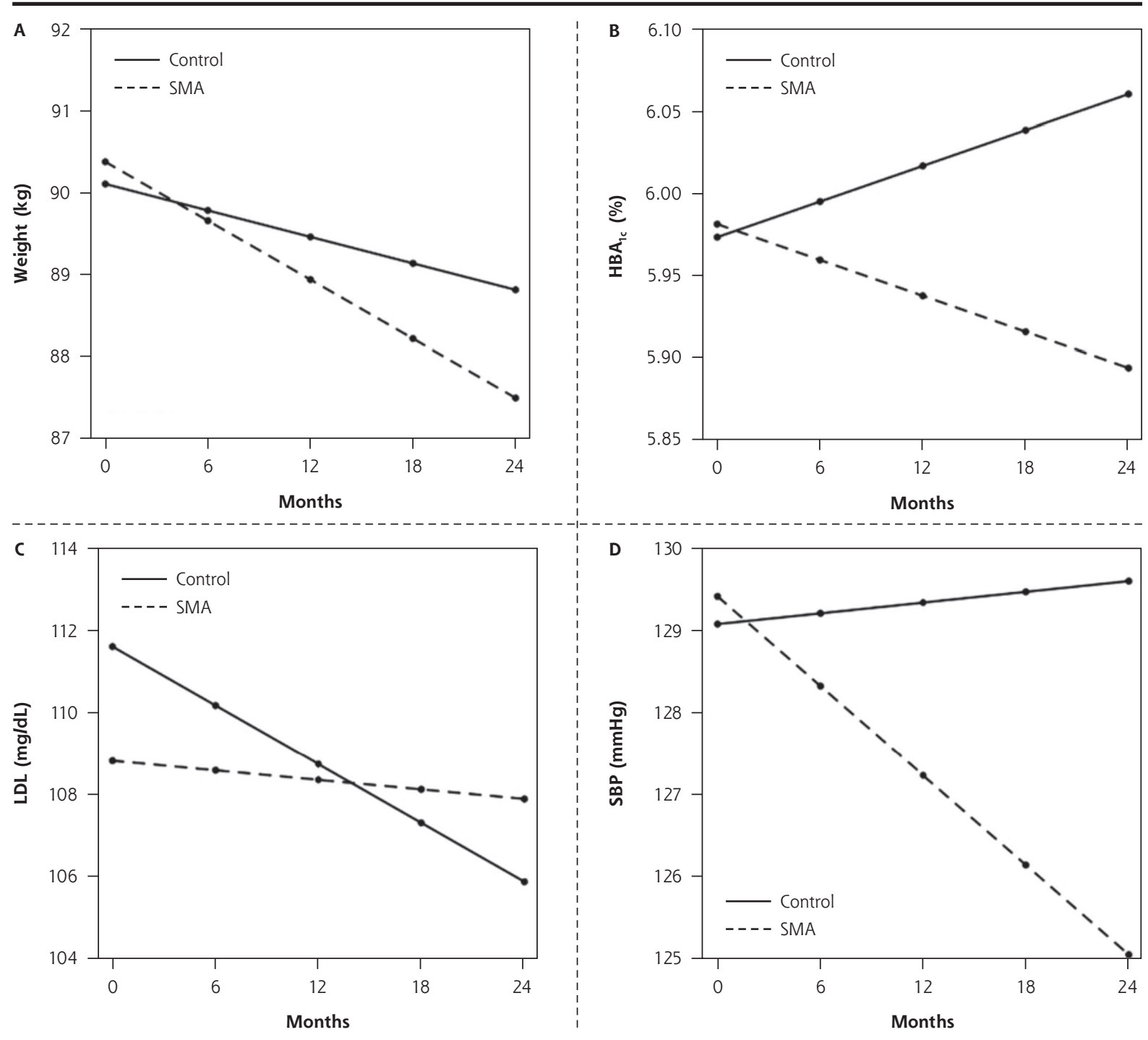

$\mathrm{HbA}_{1 \mathrm{C}}=$ hemoglobin $\mathrm{A}_{1 c} ; \mathrm{LDL}=$ low density lipoprotein; $\mathrm{SBP}=$ systolic blood pressure; SMA = shared medical appointment.

$P=.003)$. Control patients' $\mathrm{HbA}_{1 \mathrm{c}}$ increased by $0.87 \%$ vs a decline of $0.87 \%$ in the shared medical appointment group $(P=.001)$. By the conclusion of the study period, $25 \%$ of shared medical appointment patients and $16 \%$ of control group patients had been prescribed metformin $(P=.14)$. The SBP increased by $0.52 \mathrm{mmHg}$ for controls and decreased by $4.35 \mathrm{mmHg}$ for shared medical appointment patients $(P=.04)$. LDL declined by $5.72 \mathrm{mg} / \mathrm{dl}$ in the control group vs $0.9 \mathrm{mg} / \mathrm{dl}$ in the shared medical appointment group $(P=.63)$.

\section{DISCUSSION}

Over a 24-month period, patients with prediabetes participating in our shared medical appointment group lost more weight and had greater reductions in $\mathrm{HbA}_{1 \mathrm{c}}$ and SBP than control patients. The weight loss and $\mathrm{HbA}_{1 \mathrm{c}}$ reduction were not solely attributable to medication effect, even though some patients in both groups were eventually prescribed metformin. These results differed from Cole et al's randomized trial in which both groups lost weight at 3 months and partially regained some weight at 1 year, but the weight loss difference was not statistically significant. ${ }^{8}$

Our patient population is similar to Cole's study of patients with prediabetes who attended shared medical appointments in terms of age (60 years vs 58 years), BMI (32 vs 31) and baseline $\mathrm{HbA}_{1 \mathrm{c}}(6.0 \%$ vs $5.9 \%)$. A higher percentage of our patients were women ( $74 \%$ vs $46 \%)$. In Cole's study the control 
group attended 1 counseling session with a dietician while the shared medical appointment group participated in 3 nutrition-based appointments. Our control group received usual medical care which typically does not include substantial nutrition counseling. Importantly, Cole's study had a smaller sample size (34 shared medical appointment participants and 31 controls) which may have been underpowered to detect 1 $\mathrm{kg}$ of weight loss at 2 years. Our retrospective observational design leaves room for confounding variables, though we did attempt to control for this using propensity matching and conducted further analyses to determine if prescriptions started during the study could have accounted for the differences.

Our study limitations include the retrospective design, the single site of care, and possible selection bias in that patients attending a shared medical appointment may have different motivations.

In conclusion, shared medical appointments may provide an effective mode of treatment for patients diagnosed with prediabetes. The group support seems to be an important ingredient to continued progress in lifestyle modifications. As the prediabetes epidemic grows, more research is needed to determine how to best implement this option within health care systems.

To read or post commentaries in response to this article, go to https://www.AnnFamMed.org/content/19/3/258/tab-e-letters.

Key words: insulin resistance; metabolic syndrome; prediabetic state; shared medical appointments
Submitted November 25, 2019; submitted, revised, June 9, 2020; accepted June 29, 2020.

Previous presentations: Preliminary analysis of SMA and control cohort baseline data presented at SGIM Midwest Regional Meeting; September 14, 2017; Chicago, Illinois.

\section{References}

1. Ligthart S, van Herpt TT, Leening MJ, et al. Lifetime risk of developing impaired glucose metabolism and eventual progression from prediabetes to type 2 diabetes: a prospective cohort study. Lancet Diabetes Endocrinol. 2016;4(1):44-51.

2. Centers for Disease Control and Prevention. CDC 2017 Diabetes Report Card. Diabestes data and statistics. https://www.cdc.gov/ diabetes/data/index.html

3. Sörensen BM, Houben AJ, Berendschot TT, et al. Prediabetes and type 2 diabetes are associated with generalized microvascular dysfunction: the Maastricht Study. Circulation. 2016;134(18):1339-1352.

4. Mainous AG III, Tanner RJ, Baker R. Prediabetes diagnosis and treatment in primary care. J Am Board Fam Med. 2016;29(2):283-285.

5. Trento M, Passera P, Tomalino M, et al. Group visits improve metabolic control in type 2 diabetes: a 2-year follow-up. Diabetes Care. 2001;24(6):995-1000.

6. Kirsh S, Watts S, Pascuzzi K, et al. Shared medical appointments based on the chronic care model: a quality improvement project to address the challenges of patients with diabetes with high cardiovascular risk. Qual Saf Health Care. 2007;16(5):349-353.

7. Watts SA, Strauss GJ, Pascuzzi K, et al. Shared medical appointments for patients with diabetes: glycemic reduction in high-risk patients. J Am Assoc Nurse Pract. 2015;27(8):450-456.

8. Cole RE, Boyer K, Spanbauer SM, Sprague D, Bingham M. Effectiveness of pre-diabetes nutrition shared medical appointments: prevention of diabetes. Diabetes Educ. 2013;39(3):344-353. 